\title{
The Effects of Ristocetin and von Willebrand Factor on Platelet Electrophoretic Mobility
}

\author{
BARry S. Coller, Division of Hematology, Department of Medicine, \\ Health Sciences Center, State University of New York at Stony Brook, \\ Stony Brook, New York 11794
}

\begin{abstract}
A B S T RACT Ristocetin will induce the agglutination of platelets in the presence of von Willebrand factor. In previous studies, an electrostatic mechanism was proposed for this phenomenon wherein first the platelet's surface charge is reduced by the binding of ristocetin and then the von Willebrand factor acts as a bridge between platelets. To test this hypothesis, the effects of ristocetin and von Willebrand factor, singly and together, on the electrophoretic mobility of normal, trypsinized, and Bernard-Soulier platelets was measured. Ristocetin alone, at concentrations of $0.5 \mathrm{mg} / \mathrm{ml}$ or more, produced a statistically significant reduction in the electrophoretic mobility of fresh or fixed platelets. Control experiments showed that the reduction was not due to changes in the ionic milieu of the solution. Therefore, the decrease in platelet mobility is evidence for binding of ristocetin to the platelet surface. Bernard-Soulier and trypsinized platelets also had reductions in mobility with ristocetin, suggesting that ristocetin binds to the platelet at sites other than the binding site for von Willebrand factor. The presence of plasma from a patient with von Willebrand's disease did not alter the reduction in mobility of normal platelets by ristocetin. However, the reduction was markedly enhanced in the presence of normal plasma. This enhancement did not occur with BernardSoulier platelets and was inhibited by anti-Factor VIII/von Willebrand factor antiserum or trypsinization of the platelets. Thus, the enhanced reduction appears to be associated with the binding of von Willebrand factor to the platelet surface. These studies indicate that platelets undergo two changes with ristocetin and von Willebrand factor, both of which facilitate
\end{abstract}

This work was presented in part at the 1st Florence Conference on Hemostasis and Thrombosis, Florence, Italy, May 1977 and published in Clin. Res. 25: 336. (Abstr.)

This paper was awarded the 1977 Jane Nugent Cochems Prize.

Received for publication 8 August 1977 and in revised form 3 January 1978. agglutination: reduction in net surface charge and binding of von Willebrand factor, a large molecule which can serve as a bridge between platelets. In parallel studies, bovine von Willebrand factor, without ristocetin, agglutinated and reduced the electrophoretic mobility of normal but not Bernard-Soulier or trypsinized platelets; this indicates a similar mechanism of agglutination.

\section{INTRODUCTION}

In 1971, Howard and Firkin observed that the antibiotic ristocetin induced platelet aggregation in normal platelet-rich plasma (PRP) ${ }^{1}(1)$. It is now known that this phenomenon requires: $(a)$ a plasma factor (von Willebrand factor) missing or decreased in von Willebrand's disease (1-3) and (b) a platelet component missing or decreased in the Bernard-Soulier syndrome (4). The platelet component is thought to be a membrane glycoprotein $(5,6)$ which functions as the receptor for both human von Willebrand factor in the presence of ristocetin (7), and bovine von Willebrand factor (8). This platelet component is not affected by formalin treatment (9) but is altered by proteolysis with trypsin (6). Whereas data from several studies support an electrostatic mechanism of aggregation (10-13), the precise manner in which ristocetin interacts with von Willebrand factor and the platelet component remains unknown.

Earlier we investigated the effect of chemically modifying the structure of ristocetin and the closely related antibiotic, vancomycin (14). That study demonstrated the importance or ristocetin's binding properties (mediated through phenolic groups) and net positive charge in inducing platelet agglutination. In addition, it was inferred that ristocetin can bind to the platelet, even in the absence of von Willebrand

${ }^{1}$ Abbreviations used in this paper: H-S, $0.001 \mathrm{M}$ Hepes$0.15 \mathrm{M} \mathrm{NaCl}$ buffer; PRP, platelet-rich plasma. 
factor. A model was proposed wherein positively charged ristocetin binds to sites on the platelet surface and decreases the platelet's negative charge. This could directly facilitate agglutination by reducing the electrostatic repulsion between platelets. Additionally or alternatively, the binding of ristocetin could facilitate the subsequent binding of von Willebrand factor to the platelet surface. This bound von Willebrand factor could, in turn, cause agglutination by bridging between platelets in a manner analogous to immune IgM-induced agglutination of erythrocytes.

To test this hypothesis by an independent method, I have studied the effects of ristocetin and von Willebrand factor, singly and together, on the electrophoretic mobility of normal, trypsinized, and Bernard-Soulier platelets. This technique is based on the principle that the velocity of a particle subjected to a voltage gradient is determined, in part, by the electrical potential at the platelet's surface of shear (zeta potential). The zeta potential, in turn, is a reflection of the net surface charge. The studies support the hypothesis that ristocetin binds to the platelet surface and reduces the negative surface charge. In addition, I found that the subsequent binding of von Willebrand factor is associated with a further decrease in surface charge. In parallel studies, the binding of bovine von Willebrand factor to the platelet surface was also associated with a decrease in electrophoretic mobility. Finally, the binding of ristocetin to the platelet was not significantly affected by loss of the platelet component required for the binding of human and bovine von Willebrand factor, suggesting that either ristocetin does not bind to this component at all or that it constitutes only a very small percentage of the total ristocetin binding sites.

\section{METHODS}

Ristocetin sulphate (lot no. 65-956-BW) was obtained from Abbott Diagnostics, Diagnostic Products, North Chicago, Ill., who claims that this material contains $>90 \%$ ristocetin $A$ as determined by paper chromatography. Electrophoresis in $12 \%$ polyacrylamide gels (Bio-Phore, Bio-Rad Laboratories, Richmond, Calif.) in acidic buffer $(0.188 \mathrm{M}$ glycine- $0.188 \mathrm{M}$ acetate, pH 3.6) was carried out as described by Baugh et al. (15). Spectrophotometric scanning at $280 \mathrm{~nm}$ (model 2400-2, Gilford Instruments Laboratories Inc., Oberlin, Ohio) revealed a pattern very similar to that previously reported (15). There were two major peaks with the more cathodal peak containing $92 \%$ of the total absorbance and the less cathodal peak containing $7 \%$. A very small peak (@1\%) was present in a position slightly more cathodal than the largest peak. Vancomycin hydrochloride was a gift from Eli Lilly and Co. (Indianapolis, Ind.). Ristocetin and vancomycin were prepared at $50 \mathrm{mg} / \mathrm{ml}$ in $0.001 \mathrm{M}$ Hepes $-0.15 \mathrm{M} \mathrm{NaCl}(\mathrm{H}-\mathrm{S})$ buffer, pH 7.0, for all electrophoretic mobility experiments. Analytic calculations were based upon ristocetin having an $\mathrm{E}_{1 \mathrm{~cm}}^{1 \%}$ of 49 at $280 \mathrm{~nm}$ (16) and a mol wt of $2,000(17)$.

Formalin treatment of platelets and assay of von Willebrand factor were performed as described (13). Fixed platelets were stored in the formalin solution at $4^{\circ} \mathrm{C}$. For electro- phoretic mobility experiments, the formalinized platelets were washed five times in $\mathrm{H}-\mathrm{S}$ buffer and resuspended in the same buffer to a concentration of $\cong 7 \times 10^{7}$ platelets $/ \mathrm{ml}$. The $\mathrm{pH}$ of each sample was adjusted with $\mathrm{NaOH}$ or $\mathrm{HCl}$ to within $0.05 \mathrm{U}$ immediately before testing. Since $\mathrm{H}-\mathrm{S}$ has less buffering capacity at the extremes of $\mathrm{pH}$ employed, the drift in $\mathrm{pH}$ during the time required for sampling was determined. The maximum drift occurred at $\mathrm{pH} 9$ with the $\mathrm{pH}$ decreasing to 8.82 immediately after testing. Lesser degrees of drift occurred at all other $\mathrm{pH}(0.01$ at $\mathrm{pH} 2$ and 0.10 at $\mathrm{pH} 7$ ). In other experiments, fresh platelet concentrates prepared in acid citrate dextrose and kept for $1-2$ days at $4^{\circ} \mathrm{C}$ were washed three times in $\mathrm{H}-\mathrm{S}$ buffer containing $1 \mathrm{mM}$ EDTA and twice in H-S buffer without EDTA. Studies on platelets in plasma were performed on PRP from freshly drawn, citrated ( $1 / 100$ vol $40 \%$ sodium citrate) blood. The PRP was then diluted $1 / 10$ in platelet-poor plasma before testing. Normal plasma was a pool of 10 individuals' citrated, twice-centrifuged plasmas kept at $-70^{\circ} \mathrm{C}$. Severe von Willebrand plasma was obtained from a patient who had $<3 \%$ von Willebrand factor activity as determined by a ristocetininduced agglutination assay.

Rabbit anti-Factor VIII/von Willebrand factor antiserum (Behring Diagnostics, Somerville, N. J.) was adsorbed with a pellet of normal platelets as described (18) to remove any antibodies against nonspecific platelet membrane antigens. The antiserum prolonged the clumping times of formalinized platelets $(0.4 \mathrm{ml})$ in the presence of normal plasma $(50 \mu \mathrm{l})$ and ristocetin $(0.54 \mathrm{mg} / \mathrm{ml})$ from 19 to $29 \mathrm{~s}$ at a final dilution of 1/235 and from 19 to $35 \mathrm{~s}$ at 1/47. Electrophoretic mobility experiments were conducted at final dilutions of $1 / 81$ for the immune and control sera.

Washed, formalin-treated platelets $\left(1.5 \times 10^{8} / \mathrm{ml}\right)$ were incubated with trypsin (TPCK-trypsin, $253 \mathrm{U} / \mathrm{mg}$, Worthington Biochemical Corp., Freehold, N. J.) at a final concentration of $150-200 \mu \mathrm{g} / \mathrm{ml}$ for $30-35 \mathrm{~min}$ at $37^{\circ} \mathrm{C}$. The extent of the digestion was monitored by serial clumping times with normal plasma and ristocetin and when no clumping occurred within $3 \mathrm{~min}$, soybean trypsin inhibitor (Worthington Biochemical Corp.) was added in twofold excess (by weight).

Bovine fibrinogen (fraction 1, type 1, Sigma Chemical Co., St. Louis, Mo.) served as a source of bovine von Willebrand factor (8). At a final concentration of $0.5 \mathrm{mg} / \mathrm{ml}$, the clumping time of fixed, washed platelets was $15 \mathrm{~s}$. Trypsinization of the platelets prolonged this time to $>3 \mathrm{~min}$.

Electrophoretic mobility of platelets was determined in a 1-mm radius cylindrical cell apparatus (Mark I, Rank Bros., Bottisham, Cambs., U. K.) submerged in a $25^{\circ} \mathrm{C}$ water bath by visually measuring (with the aid of a $\times 400$ microscope) the time required for a platelet to traverse a calibrated distance when subjected to a voltage gradient (19). Studies were performed with a $3.82-\mathrm{V} / \mathrm{cm}$ gradient maintained between two grey-platinum electrodes which resulted in the generation of a current of $1.55 \pm 0.05 \mathrm{~mA}$ for platelets in $\mathrm{H}-\mathrm{S}$ buffer. In no experiment did the current exceed $2 \mathrm{~mA}$, the value at which thermal alterations become significant. The microscope was focused on the stationary plane $(0.293 \mathrm{~mm}$ from the inner chamber wall) and only those platelets in focus were measured. This setting was confirmed by measuring the mobility of erythrocytes in $0.15 \mathrm{M} \mathrm{NaCl}-0.0001 \mathrm{M} \mathrm{NaHCO}$, pH 7.2. The observed value was $-1.07 \pm 0.07 \mu \mathrm{m} / \mathrm{s} / \mathrm{V}$ per $\mathrm{cm}$ (mean \pm SD) which is in excellent agreement with the value of $-1.08 \pm 0.03 \mu \mathrm{m} / \mathrm{s} / \mathrm{V}$ per cm obtained by Seaman (20). All observations were made on single, unclumped platelets; even in the presence of significant clumping, sufficient numbers of single platelets remained. It is unlikely that the unclumped platelets were an unrepresentative subpopulation since, as has also been observed by others (21), the platelet 
clumps had mobilities essentially identical to those of single platelets. Each platelet was first timed going in one direction; then the polarity of the voltage gradient was reversed and the same platelet was timed going in the opposite direction. If the lower of the two readings was $>15 \%$ less than the higher, this was taken to indicate that unequal drift (thermal or mechanical) was present during the measurements and the values were excluded from the calculations. A minimum of 20 values ( 10 platelets measured in two directions) were obtained for each sample and the platelets' electrophoretic mobility $(u)$ was calculated from the equation $u=v / V G$ where $v=$ platelets' velocity in micrometers per second and $V G=$ voltage gradient in volts per centimeter. A mean and SEM was calculated for each sample. Differences between samples were analyzed by unpaired Student's $t$ test. In general, samples were significantly different from each other when one value was $4 \%$ greater than the other. Where experiments were repeated several times, the mean values were averaged and the standard error of the average computed. Statistical significance for these data were determined by paired Student's $t$ test. All measurements of platelets in the presence of plasma or bovine fibrinogen were corrected for differences in viscosity by multiplying the observed electrophoretic mobility by the sample's relative viscosity (sample viscosity/buffer viscosity). At the concentrations employed, ristocetin produced no significant change in viscosity. Viscosity was measured at $25^{\circ} \mathrm{C}$ either in an Ostwald viscometer (Cannon Instrument Co., State College, $\mathrm{Pa}$.) or a falling ball viscometer (Roger Gilmont Instruments, Inc., Great Neck, N. Y.).

PRP from a patient (A. J.) with Bernard-Soulier syndrome, an account of whose disease has been previously published $(4,22)$, was obtained by gravity sedimentation of whole, citrated blood. The PRP was then treated with formalin and kept at $4^{\circ} \mathrm{C}$. A control sample from a normal person was prepared in the same way.

\section{RESULTS}

11 different samples of formalin-treated platelets, washed and resuspended in $\mathrm{H}-\mathrm{S}$ at $\mathrm{pH} 7$ and tested on 36 occasions, had an electrophoretic mobility of $-0.833 \pm 0.004 \mu \mathrm{m} / \mathrm{s} / \mathrm{V}$ per $\mathrm{cm}($ mean $\pm \mathrm{SEM})$. Washed, fresh platelets had essentially the same mobility as the fixed platelets $(-0.842 \mu \mathrm{m} / \mathrm{s} / \mathrm{V}$ per $\mathrm{cm} ; n=2)$, whereas platelets in citrated PRP had a slightly greater mobility $(-0.895 \mu \mathrm{m} / \mathrm{s} / \mathrm{V}$ per $\mathrm{cm} ; n=4)$. The electrophoretic mobility of fixed platelets varied as a function of $\mathrm{pH}$ much like that reported for fresh, washed platelets (23-25); it was positive at $\mathrm{pH} 2$, because 0 (isoelectric point) at $\cong \mathrm{pH} 3$, and then became increasingly negative at higher $\mathrm{pH}$ until it reached a plateau between $\mathrm{pH} 7$ and 8 .

At concentrations as low as 0.5 and $0.6 \mathrm{mg} / \mathrm{ml}$, ristocetin alone produced small but statistically significant decreases $(P<0.0025$ and 0.001 , by paired Student's $t$ test, respectively) in the electrophoretic mobility of formalin-treated platelets in H-S buffer at pH 7 (Fig. 1). Increasing the ristocetin concentration resulted in even greater decreases in electrophoretic mobility. Platelet clumping was observed at concentrations of ristocetin $(>3 \mathrm{mg} / \mathrm{ml})$ which caused at least a $12 \%$ reduction in mobility. Washing the platelets

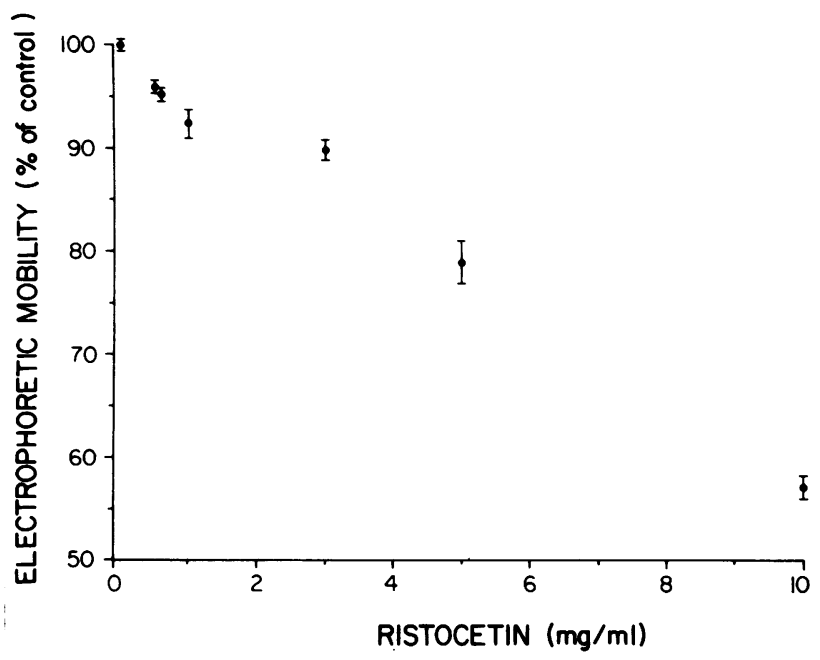

Figure 1 Formalin-fixed platelets were washed and resuspended in $\mathrm{H}-\mathrm{S}$ buffer. Ristocetin $(50 \mathrm{mg} / \mathrm{ml})$ in the same buffer was added, the $\mathrm{pH}$ adjusted to $7.00 \pm 0.05$, and the electrophoretic mobility determined. Each experiment involved at least 20 velocity measurements ( 10 platelets measured going first in one direction and then the other). A mean and SEM for the 20 observations in each experiment was calculated. Since multiple experiments were performed at all ristocetin concentrations except $10 \mathrm{mg} / \mathrm{ml}$ ( 5 at 0.5 , 15 at $0.6,8$ at $1.0,4$ at 3.0 and 5 at $5.0 \mathrm{mg} / \mathrm{ml}$ ), the points represent the average of the means determined for each experiment and the bars represent the SEM for those means. At $10 \mathrm{mg} / \mathrm{ml}$, the mean and SEM for the 20 observations in the single experiment performed is shown.

with ristocetin-free buffer completely reversed the decrease in mobility. Fresh washed platelets also showed a decrease in electrophoretic mobility when ristocetin was added; at $0.6 \mathrm{mg} / \mathrm{ml}$ there was a $6.1 \pm 1.3 \%$ decrease, and at $3 \mathrm{mg} / \mathrm{ml}$ there was a $7.9 \pm 1.3 \%$ decrease. Since changes in ionic strength may alter the electrophoretic mobility of charged particles, control experiments were conducted with increasing concentrations $\mathrm{CaCl}_{2}$ to simulate the changes in the ionic environment which may have been caused by ristocetin (which will have a charge between +1 and +2 at $\mathrm{pH} 7.0$ ) (26). Concentrations of $\mathrm{CaCl}_{2}$ as high as $3 \mathrm{mM}$ (equivalent in molar concentration to $6 \mathrm{mg} / \mathrm{ml}$ of ristocetin) produced no significant reduction in electrophoretic mobility; even at $5.8 \mathrm{mM}$ (equivalent to $11.6 \mathrm{mg} / \mathrm{ml}$ ristocetin) there was only a $6 \%$ decrease. In addition, at concentrations up to $2 \mathrm{mg} / \mathrm{ml}$ (the highest tested), ristocetin had no effect on the electrophoretic mobility of erythrocytes suspended in H-S buffer, $\mathrm{pH} 7.0$ $(u=-1.08 \pm 0.01 \mu \mathrm{m} / \mathrm{s} / \mathrm{V}$ per $\mathrm{cm}$ at $2 \mu \mathrm{mg} / \mathrm{ml}$ and $-1.10 \pm 0.011 \mu \mathrm{m} / \mathrm{s} / \mathrm{V}$ per $\mathrm{cm}$ without ristocetin: $P$ $>0.1$ ). Vancomycin had no effect on platelet mobility at concentrations up to $2 \mathrm{mg} / \mathrm{ml}$ in five separate experiments $(-0.785 \pm 0.023 \mu \mathrm{m} / \mathrm{s} / \mathrm{V}$ per $\mathrm{cm}$ without vancomycin and $-0.795 \pm 0.026 \mu \mathrm{m} / \mathrm{s} / \mathrm{V}$ per $\mathrm{cm}$ at $2 \mathrm{mg} / \mathrm{ml}$ 
vancomycin). At $5 \mathrm{mg} / \mathrm{ml}$, vancomycin produced platelet clumping even in the absence of plasma and this was associated with a $25 \%$ decrease in mobility.

Ristocetin's effect on electrophoretic mobility was $\mathrm{pH}$ dependent (Fig. 2). At pH 9 (above ristocetin's isoionic point of $8.3-8.5)$ (26), ristocetin $(5 \mathrm{mg} / \mathrm{ml})$ produced no decrease in electrophoretic mobility; at lower $\mathrm{pH}$ (that is, as ristocetin became positively charged), the effect became more pronounced. The platelets' isoelectric point increased from 3 to 4 in the presence of ristocetin.

The addition of either normal or von Willebrand plasma $(12 \pm 2 \% \mathrm{vol} / \mathrm{vol})$ to fixed, washed platelets produced $\cong 5 \%$ decrease in electrophoretic mobility after correcting for changes in viscosity. There was no significant difference in mobility in the presence of normal or von Willebrand plasma $(-0.813 \pm 0.013$ $\mu \mathrm{m} / \mathrm{s} / \mathrm{V}$ per $\mathrm{cm}$ and $-0.816 \pm 0.011 \mu \mathrm{m} / \mathrm{s} / \mathrm{V}$ per $\mathrm{cm}$, respectively). There was, however, a marked difference in response when ristocetin was added to platelets in the presence of normal and von Willebrand plasma (Fig. 3). With von Willebrand plasma, ristocetin produced the same small decrease in mobility as without any plasma. However, there was a dramatic enhancement of the reduction in mobility when ristocetin was added to platelets in the presence of normal plasma. Washing the platelets once in eightfold excess buffer reversed the decrease in mobility. Platelets kept in the formalin solution for up to 1 mo showed the same response, but more prolonged storage led to a deterioration in response. Fresh, washed platelets

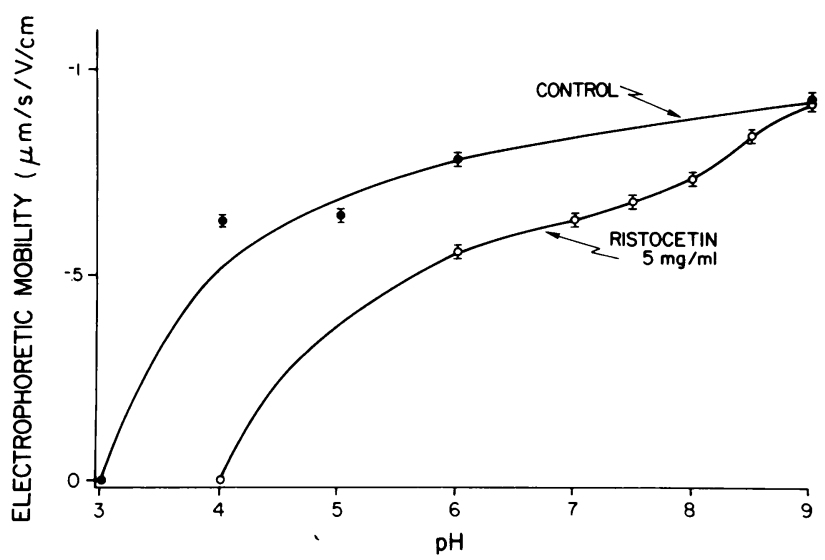

Figure 2 Fixed, washed platelets were resuspended in $\mathrm{H}-\mathrm{S}$ buffer with or without $5 \mathrm{mg} / \mathrm{ml}$ ristocetin. Immediately before testing, the $\mathrm{pH}$ was adjusted to the indicated values using concentrated $\mathrm{HCl}$ and $\mathrm{NaOH}$. A small amount of $\mathrm{pH}$ drift occurred during testing (maximum of $0.18 \mathrm{U}$ at $\mathrm{pH} 9$ ). Ristocetin did not produce a significant decrease in mobility at $\mathrm{pH} 9$, but caused increasing reductions as the $\mathrm{pH}$ was lowered. Note the change in platelet pI from 3 to 4 . The points and bars represent the mean \pm SEM for the $20 \mathrm{ob}$ servations made at each $\mathrm{pH}$.

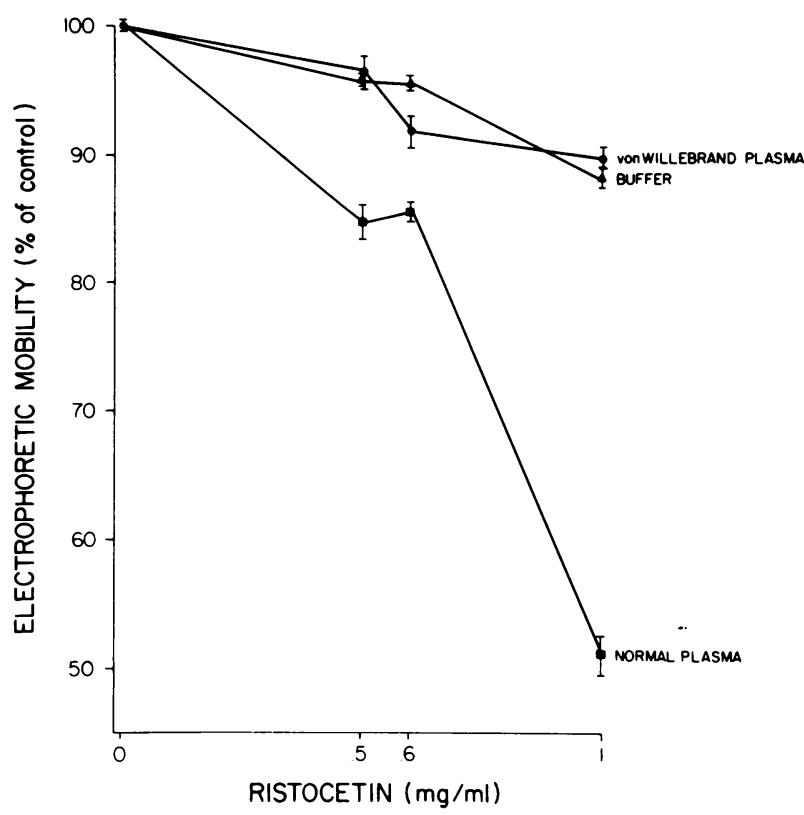

FIGURE 3 The effect of ristocetin on the electrophoretic mobility of platelets in the presence of buffer, severe von Willebrand plasma, or normal plasma. Fixed platelets were washed and resuspended in $\mathrm{H}-\mathrm{S}$ buffer, $\mathrm{pH} 7.00$, with or without von Willebrand or normal plasma (12 $2 \%)$. Ristocetin $(50 \mathrm{mg} / \mathrm{ml})$ was added to achieve the final concentrations indicated and the electrophoretic mobility determined. The mobility of platelets in buffer alone $(n=9)$ was $-0.850 \pm 0.006 \mu \mathrm{m} / \mathrm{s} / \mathrm{V}$ per $\mathrm{cm}$ and the viscosity-corrected mobilities for platelets with normal or von Willebrand plasma were $-0.813 \pm 0.013(n=9)$ and $-0.816 \pm 0.011(n=4) \mu \mathrm{m} / \mathrm{s} /$ $\mathrm{V}$ per $\mathrm{cm}$, respectively. A total of 10 experiments were performed without plasma, each consisting of at least 20 observations ( 3 at $0.5,6$ at 0.6 , and 1 at $1 \mathrm{mg} / \mathrm{ml}$ ristocetin); 10 experiments were performed with normal plasma $(3,6$, and 1 , respectively) and 5 experiments with von Willebrand plasma $(3,1$, and 1 , respectively). A mean value was determined in each experiment. The points represent the average \pm SEM of those means except at $1 \mathrm{mg} / \mathrm{ml}$ (and $0.6 \mathrm{mg} / \mathrm{ml}$ ristocetin with von Willebrand plasma) where the mean and SEM of the 20 observations of single experiments are given.

showed the same response as fixed platelets (a decrease of $14 \pm 1.2 \%$ with normal plasma and $0.6 \mathrm{mg} / \mathrm{ml}$ ristocetin compared to $4.6 \pm 1.3 \%$ with von Willebrand plasma and ristocetin). Similarly, fresh, normal PRP had a $12.2 \pm 1 \%$ reduction in mobility upon the addition of $1.8 \mathrm{mg} / \mathrm{ml}$ ristocetin. When the percentage of normal plasma was varied, it was found that the maximum decrease in fixed platelets' mobility produced by ristocetin $(0.6 \mathrm{mg} / \mathrm{ml})$ occurred at $\cong 17 \%$ plasma.

The effect of monospecific anti-Factor VIII/von Willebrand factor serum is shown in Table I. Platelets in H-S buffer had a small decrease in mobility when ristocetin was added. The presence of anti-Factor VIII/ von Willebrand factor serum did not affect this small decrease in mobility produced by ristocetin. In the 
TABLE I

The Effects of Normal Plasma and Ristocetin on the Electrophoretic Mobility of Normal, Trypsinized, and Bernard-Soulier Platelets

\begin{tabular}{|c|c|c|c|c|c|c|}
\hline \multirow{2}{*}{$\begin{array}{l}\text { Experi- } \\
\text { ment }\end{array}$} & \multirow[b]{2}{*}{ Platelets } & \multicolumn{2}{|c|}{ Additions } & \multicolumn{2}{|c|}{ Ristocetin (mg/ml) } & \multirow{2}{*}{$\begin{array}{c}\text { Reduction } \\
\text { with ristocetin }\end{array}$} \\
\hline & & Plasma & Serum & 0 & 0.6 & \\
\hline & & $10 \% \mathrm{vol} / \mathrm{vo}$ & & $\begin{array}{r}\text { Electrophoretic mo } \\
\text { mea }\end{array}$ & $\begin{array}{l}\text { ity }(\mu m / s / N \text { per } \mathrm{cm}) \\
\text { SEM }\end{array}$ & $\%$ \\
\hline \multirow[t]{5}{*}{1} & $\mathbf{N}^{*}$ & - & - & $-0.833 \pm 0.011$ & $-0.789 \pm 0.013$ & 5.3 \\
\hline & $\mathbf{N}$ & - & Anti-VIII/vWf & $-0.816 \pm 0.015$ & $-0.774 \pm 0.013$ & 5.1 \\
\hline & $\mathbf{N}$ & + & - & $-0.798 \pm 0.008$ & $-0.712 \pm 0.009$ & 11.0 \\
\hline & $\mathbf{N}$ & + & Control & $-0.802 \pm 0.009$ & $-0.693 \pm 0.009$ & 13.6 \\
\hline & $\mathrm{N}$ & + & Anti-VIII/vWf & $-0.804 \pm 0.011$ & $-0.770 \pm 0.011$ & 4.2 \\
\hline \multirow[t]{4}{*}{2} & $\mathbf{N}$ & - & & $-0.835 \pm 0.010$ & $-0.799 \pm 0.011$ & 4.3 \\
\hline & $\mathbf{N}$ & + & & $-0.789 \pm 0.012$ & $-0.675 \pm 0.009$ & 14.4 \\
\hline & $\mathbf{T}$ & - & & $-0.825 \pm 0.011$ & $-0.779 \pm 0.012$ & 5.6 \\
\hline & $\mathrm{T}$ & + & & $-0.741 \pm 0.010$ & $-0.720 \pm 0.010$ & 2.8 \\
\hline \multirow[t]{4}{*}{3} & $\mathrm{~N}$ & - & & $-0.841 \pm 0.011$ & $-0.812 \pm 0.011$ & 3.5 \\
\hline & $\mathbf{N}$ & + & & $-0.781 \pm 0.009$ & $-0.665 \pm 0.009$ & 14.9 \\
\hline & B-S & - & & $-0.658 \pm 0.013$ & $-0.625 \pm 0.011$ & 5.0 \\
\hline & B-S & + & & $-0.621 \pm 0.009$ & $-0.580 \pm 0.009$ & 6.6 \\
\hline
\end{tabular}

* N, normal; T, trypsinized; B-S, Bernard-Soulier; vWf, von Willebrand factor.

presence of normal plasma or normal plasma with control serum, enhanced reduction was observed when ristocetin was added. An equivalent amount of antiFactor VIII/von Willebrand factor serum completely abolished the enhancement of reduction in mobility produced by normal plasma. However, it did not prevent the small reduction attributable to ristocetin alone.

After trypsinization for 30-35 min, fixed, washed platelets failed to agglutinate in the presence of normal plasma and ristocetin. Trypsinization did not alter the electrophoretic mobility of the platelets (Table I). The trypsinized platelets showed the same ristocetin-induced reduction in electrophoretic mobility as untreated platelets. However, when ristocetin was added in the presence of $10 \%$ normal plasma, the enhanced reduction seen with untreated platelets was completely abolished.

The formalin-treated and washed Bernard-Soulier platelets had significantly lower electrophoretic mobility than normal platelets $(-0.658 \pm 0.013$ and -0.671 $\pm 0.016 \mu \mathrm{m} / \mathrm{s} / \mathrm{V}$ per $\mathrm{cm}$ on two occasions; $P<0.001$ each time compared to control; Tables I and II). The Bernard-Soulier platelets had the same percentage reduction in electrophoretic mobility as normal platelets when ristocetin was added. However, unlike normal platelets, the presence of normal plasma did not enhance the reduction in electrophoretic mobility of Bernard-Soulier platelets upon the addition of ristocetin.
The effect of increasing concentrations of bovine von Willebrand factor on the electrophoretic mobility of normal formalin-treated platelets in H-S buffer is shown in Fig. 4. There was a dose-dependent reduction in electrophoretic mobility which leveled off at concentrations of protein (containing both fibrinogen and von Willebrand factor) above $5 \mathrm{mg} / \mathrm{ml}$. The lowest concentration of bovine von Willebrand factor which caused rapid macroscopic clumping of platelets $(0.5$ $\mathrm{mg} / \mathrm{ml}$ ) produced a $14 \%$ decrease in platelet mobility. In contrast to normal platelets, both trypsinized and Bernard-Soulier platelets did not have a significant

TABLE II

The Effect of Bovine Fibrinogen on the Electrophoretic Mobility of Normal, Trypsonized, and BernardSoulier Platelets

\begin{tabular}{lccc}
\hline & \multicolumn{2}{c}{ Bovine von Willebrand factor $(\mathrm{mg} / \mathrm{ml})^{*}$} & \\
\cline { 2 - 3 } Platelets & 0 & 1 & $\begin{array}{c}\text { Reduction from } \\
\text { control }\end{array}$ \\
\hline \multicolumn{3}{c}{ Electrophoretic mobility $(\mu \mathrm{m} / \mathrm{s} / \text { Ner } \mathrm{cm})^{*}$} \\
mean \pm SEM & $\%$ \\
$\mathrm{~N} t$ & $-0.840 \pm 0.010$ & $-0.673 \pm 0.011$ & 20.0 \\
$\mathrm{~T}$ & $-0.834 \pm 0.008$ & $-0.794 \pm 0.012$ & 4.8 \\
B-S & $-0.671 \pm 0.016$ & $-0.648 \pm 0.012$ & 3.4 \\
\hline
\end{tabular}

* Expressed as protein concentration of bovine fibrinogen containing von Willebrand factor.

$\ddagger N$, normal; T, Trypsinized; B-S, Bernard-Soulier. 


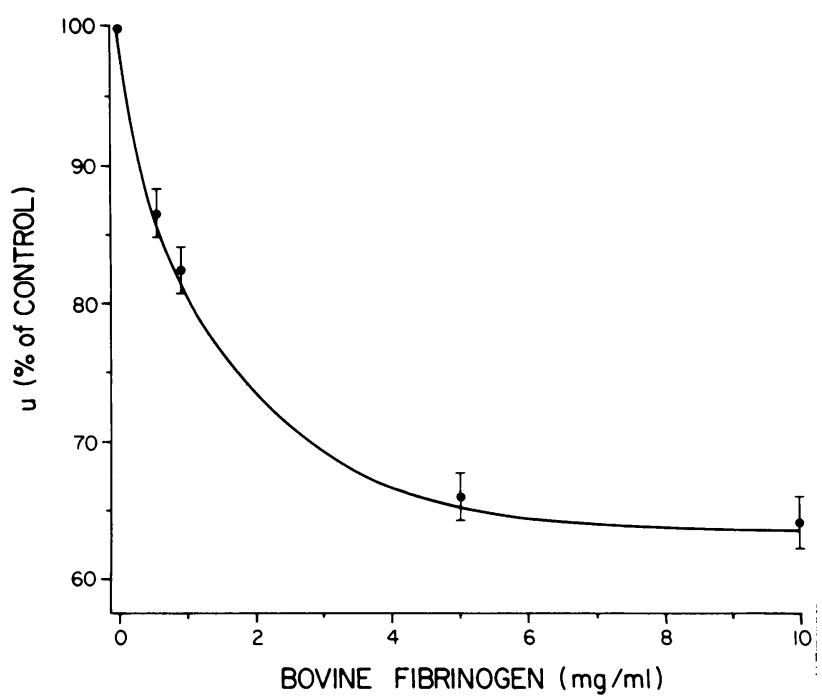

Figure 4 The effect of increasing concentrations of bovine fibrinogen, containing bovine von Willebrand factor, on the electrophoretic mobility of normal fixed platelets. Fixed platelets were washed and resuspended in $\mathrm{H}-\mathrm{S}$ buffer $\mathrm{pH}$ 7.0 and dry bovine fibrinogen was added to achieve the indicated concentrations.

decrease in electrophoretic mobility when bovine von Willebrand factor was added (Table II).

\section{DISCUSSION}

The electrophoretic mobility values obtained for fresh, washed platelets and platelets in PRP in the present study, are in excellent agreement with previous reports (21, 23-25). Since fixed and fresh platelets had essentially the same electrophoretic mobilities throughout a range of $\mathrm{pH}$ values, it appears that the formaldehyde treatment did not significantly alter the surface charge properties. This was also supported by finding that fixed Bernard-Soulier platelets had slower mobility than fixed normal platelets, confirming a finding originally made with fresh platelets (27). Despite this, to avoid conclusions which might be the result of fixation-induced alterations, the observed effects of ristocetin on fixed platelets were confirmed using fresh, washed platelets and(or) fresh platelets in PRP.

Ristocetin alone produced significant reductions in platelet electrophoretic mobility at concentrations as low as $0.5 \mathrm{mg} / \mathrm{ml}$ (the dose used in the clumping assay). This effect was not due to a change in the suspending solution's ionic strength or the presence of a cationic compound in solution since: $(a)$ the addition of $\mathrm{CaCl}_{2}$ to platelets reduced mobility only at molar concentrations $\sim 20$-fold higher than those effective with ristocetin, and $(b)$ the electrophoretic mobility of erythrocytes was unaffected by a concentration of ristocetin fourfold in excess of that which produced changes with platelets. In addition, the inability of vancomycin (an antibiotic similar to ristocetin but that does not agglutinate platelets at low concentrations) to reduce platelet mobility at a concentration fourfold in excess of that at which ristocetin did, lends further support to the specificity of interaction between ristocetin and platelets. The upper $\mathrm{pH}$ limit for ristocetin's effect on mobility coincides both with ristocetin's isoionic point and the upper $\mathrm{pH}$ limit of ristocetin-induced platelet agglutination, supporting the hypothesis that ristocetin's contribution of positive charge to the platelet surface is necessary, if not sufficient, to initiate agglutination in the presence of the von Willebrand factor. That ristocetin does not bind exclusively either to surface-bound Factor VIII/von Willebrand factor or to the proposed platelet receptor for von Willebrand factor is suggested by the failure of anti-Factor VIII/von Willebrand factor serum, platelet trypsinization, or substitution of Bernard-Soulier platelets to affect the change in mobility produced by ristocetin.

There was no electrostatic evidence for an interaction between von Willebrand factor and platelets in the absence of ristocetin. However, the addition of ristocetin to platelets in the presence of normal but not von Willebrand plasma, produced a dramatic enhancement of the decrease in mobility attributable to the ristocetin alone. Under the conditions used in the von Willebrand factor assay, the electrophoretic mobility was reduced by $\cong 15 \%$ and macroscopic clumping occurred. Muraki et al. (28), in studies performed simultaneously but independently, reported essentially identical results in a preliminary communication using diluted normal or von Willebrand PRP. However, these authors did not report a significant change in platelet electrophoretic mobility with 1 $\mathrm{mg} / \mathrm{ml}$ ristocetin alone. Since the changes at low concentrations are small but statistically significant, the effect might be missed unless a sufficient number or experiments are performed. The enhanced reduction in electrophoretic mobility found with normal plasma probably results from the binding of von Willebrand factor to the platelet surface since it could be abolished by either adding anti-Factor VIII/von Willebrand factor serum or substituting trypsinized or BernardSoulier platelets. Recent studies showing that von Willebrand factor will only bind to platelets when ristocetin is present and that trypsinized platelets and Bernard-Soulier do not bind von Willebrand factor even when ristocetin is present $(7,29)$ are consistent with this interpretation.

Bovine von Willebrand factor, the active agent in bovine fibrinogen preparations $(30,31)$, agglutinates normal but not Bernard-Soulier platelets (32). Agglutination by bovine von Willebrand factor has many 
features in common with agglutination by the combination of human von Willebrand and ristocetin $(8,10-13)$. The present study shows another parallel between these systems, since concentrations which gave clumping $(0.5 \mathrm{mg} / \mathrm{ml})$ also caused a $14 \%$ reduction in electrophoretic mobility. At high concentrations, the decrease in mobility levelled off, perhaps reflecting saturation of a limited number of receptors. Gröttum (21) has shown that bovine platelet fibrinogen (presumably contaminated with some bovine von Willebrand factor), agglutinated platelets at a concentration which reduced their electrophoretic mobility by $15 \%$. Experiments with trypsinized and Bernard-Soulier platelets suggest that the decreased mobility is due to binding of the bovine von Willebrand factor to the platelet and are in accord with the study of Kirby and Mills (8) correlating platelet binding and agglutination.

The proposed mechanism for ristocetin-induced agglutination does not include any effects of ristocetin on the fluid-phase von Willebrand factor since the data currently available do not support such an interaction within the limits of dose and time encountered in the von Willebrand factor assay. In unpublished studies, treatment of von Willebrand factor with ristocetin (and then removing the latter) did not produce a form of von Willebrand factor which could agglutinate platelets in the absence of added ristocetin. ${ }^{2}$ Recently, Floyd et al. (33) showed that the migration of von Willebrand factor in the ultracentrifuge shifted to a slightly higher apparent molecular weight (aggregation) when incubated with ristocetin at a l-mg/ $\mathrm{ml}$ concentration for $5 \mathrm{~min}$. Apparently, no observable changes occurred at the lower concentrations and shorter times involved in the von Willebrand factor assay. Thus, additional evidence will be required to establish a primary role for a ristocetin-von Willebrand factor interaction in inducing agglutination.

Implications of the ristocetin-induced platelet agglutination phenomenon for normal hemostasis have remained elusive. The prevailing view is that the von Willebrand factor is involved in adhesion of platelets to the subendothelium of the blood vessel (34), perhaps because the von Willebrand factor is localized in this area after synthesis by endothelial cells $(35,36)$. However, in the platelet retention in glass-bead filters test (37) and the ristocetin phenomenon, the von Willebrand factor mediates platelet-to-platelet interactions, not platelet adhesion. Moreover, there is evidence that fluid-phase von Willebrand factor will not bind to unaltered platelets. Whereas platelets exposed to ristocetin will bind von Willebrand factor and the present study suggests that ristocetin's effect on platelets is related to changes in surface charge, an

\footnotetext{
${ }^{2}$ Coller, B. S., and H. R. Gralnick. Unpublished observa-
} tions. alternative hypothesis may be advanced. Initially platelets may adhere to subendothelial surfaces by a process which does not require the von Willebrand factor (analogous, perhaps to the von Willebrand factor independent initial adherence of platelets to glass beads) (37). This adherence results in a change of the platelets' surface charge properties similar to that induced by ristocetin. This, in turn, then permits the binding of von Willebrand factor to the platelet. By virtue of its large molecular radius and repetitive identical subunit structure, the von Willebrand factor is ideally suited for acting as a bridge between these adhering platelets, linking them one to another. This stabilizes the platelet's interaction with the subendothelium and also helps to initiate the platelets' release of ADP which then recruits additional platelets to the aggregate.

\section{ACKNOWLEDGMENTS}

I want to thank Dorene Turi for outstanding technical assistance and Ms. Lynn Marelli for excellent secretarial assistance. I am grateful to Dr. Margaret Johnson for providing a sample of Bernard-Soulier platelets.

These studies were performed under a grant from the National Heart, Lung, and Blood Institute (HL 19278).

\section{REFERENCES}

1. Howard, M. A., and B. G. Firkin. 1971. Ristocetin-a new tool in the investigation of platelet aggregation. Thromb. Diath. Haemorrh. 26: 362-369.

2. Weiss, H. J., J. Rogers, and H. Brand. 1973. Defective ristocetin-induced platelet aggregation in von Willebrand's disease and its correction by factor VIII. J. Clin. Invest. 52: 2697-2707.

3. Meyer, D., C. S. P. Jenkins, D. Dreyfus, E. Fressinand, and M-J. Larrieu. 1974. von Willebrand factor and ristocetin. II. Relationship between Willebrand factor, Willebrand antigen, and factor VIII activity. $B r . J$. Haematol. 28: 579-599.

4. Weiss, H. J., T. B. Tschopp, H. R. Baumgartner, I. Sussman, M. M. Johnson, and J. J. Egan. 1974. Decreased adhesion of giant (Bernard-Soulier) platelets to subendothelium. Am. J. Med. 57: 920-925.

5. Jenkins, C. S. P., D. R. Phillips, K. J. Clemetson, D. Meyer, M-J. Larrieu, and E. F. Luscher. 1976. Platelet membrane glycoprotein implicated in ristocetin-induced aggregation. Studies on the proteins on platelets from patients with Bernard-Soulier syndrome and von Willebrand's disease. J. Clin. Invest. 57: 112-124.

6. Caen, J. P., A. T. Nurden, C. Jeanneau, H. Michel, G. Tobelem, S. Levy-Toledano, Y. Sultan, F. Valensi, and J. Bernard. 1976. Bernard-Soulier syndrome: a new glycoprotein abnormality. Its relationship with platelet adhesion to subendothelium and with the factor VIII von Willebrand protein. J. Lab. Clin. Med. 87: 586-596.

7. Zucker, M. B., K. Sook-Ja, J. McPherson, and R. A. Grant. 1977. Binding of factor VIII to platelets in the presence of ristocetin. Br. J. Haematol. 35: 535-549.

8. Kirby, E., and D. C. B. Mills. 1975. The interaction of bovine factor VIII with human platelets. J. Clin. Invest. 56: $491-502$

9. Allain, J. P., H. A. Cooper, R. H. Wagner, and K. M. 
Brinkhous. 1975. Platelets fixed with paraformaldehyde: a new reagent for assay of von Willebrand factor and platelet aggregation factor. J. Lab. Clin. Med. 85: 318-328.

10. Howard, M. A. 1975. Inhibition and reversal of ristocetininduced platelet aggregation. Thromb. Res. 6: 489-499.

11. Kattlove, H. E., and M. H. Gomez. 1975. Studies on the mechanism of ristocetin-induced platelet aggregation. Blood. 45: 91-96.

12. Kirby, E. P. 1975. Evans Blue: a specific inhibitor of factor VIII-induced platelet agglutination. Thromb. Diath. Haemorrh. 34: 770-779.

13. Coller, B. S., B. R. Franza, Jr., and H. R. Gralnick. 1976. The $\mathrm{pH}$ dependence of quantitative ristocetin-induced platelet aggregation: theoretical and practical implications-a new device for maintenance of platelet-rich plasma pH. Blood. 47: 841-854.

14. Coller, B. S., and H. R. Gralnick. 1977. Studies on the mechanism of ristocetin-induced platelet agglutination. Effects of structural modification of ristocetin and vancomycin. J. Clin. Invest. 60: 302-312.

15. Baugh, R. F., J. E. Brown, and C. Hougie. 1977. Preparation and platelet aggregating activity of ${ }^{125}$ I-labeled ristocetin. Anal. Biochem. 78: 39-46.

16. Nieto, M., and H. R. Perkins. 1971. The specificity of combination between ristocetins and peptides related to bacterial cell wall mucopeptide precursors. Biochem. J. 125: 845-852.

17. Perkins, H. R., and M. Nieto. 1974. The chemical basis for the action of the vancomycin group of antibiotics. Ann. N. Y. Acad. Sci. 235: 348-363.

18. Coller, B. S., R. J. Hirschmann, and H. R. Gralnick. 1975. Studies of the factor VIII/von Willebrand factor antigen on human platlets. Thromb. Res. 6: 469-480.

19. Bangham, A. K., and D. H. Heard. 1959. An apparatus for microelectrophoresis of small particles. Nature (Lond.). 182: 642-644.

20. Seaman, G. V. F. 1975. Electrokinetic behavior of red cells. In The Red Cell. Surgenor, editor. Academic Press, Inc., New York. 2: 1136-1229.

21. Gröttum, K. A. 1969. Platelet surface charge and aggregation. Effects of polyelectrolytes. Thromb. Diath. Haemorrh. 21: 450-462.

22. Walsh, P. N., C. B. Mills, F. I. Pareti, G. J. Stewart, D. E. Macfarlane, M. M. Johnson, and J. J. Egan. 1975. Hereditary giant platelet syndrome. Absence of collagen-induced coagulant activity and deficiency of factor XI binding to platelets. Br. J. Haematol. 29: 639655.

23. Gröttum, K. A. 1973. Electrophoresis of blood platelets and erythrocytes. A study in healthy persons and pa- tients with haematological diseases, prosthetic heart valves, virus infections and hyperlipaemia. Scand. J. Haematol. 11: 166-176.

24. Zucker, M. B., and R. U. Levine. 1963. Microelectrophoresis of washed and unwashed human blood platelets, with additional studies of platelets from patients with von Willebrand's disease and thrombasthenia. Thromb. Diath. Haemorrh. 10: 1-8.

25. Seaman, G. V. F., and P. S. Vassar. 1966. Changes in the electrokinetic properties of platelets during their aggregation. Arch. Biochem. Biophys. 117: 10-17.

26. Lomakina, N. N., L. I. Muravieva, and M. S. Yarina. 1970. Molecular weight and the number of ionogenic groups of ristomycins and close antibiotics. Antibiotiki (Mosc.). 15: $21-24$.

27. Gröttum, K. A., and N. O. Solum. 1969. Congenital thrombocytopenia with giant platelets: a defect in the platelet membrane. Br. J. Haematol. 16: 277-290.

28. Muraki, H., K. Watanabe, Y. Ando, K. Toyama, and M. Hasegawa. 1977. Reduction of surface negative charge in human platelets by ristocetin. Thromb. Haemostasis. 38: 69. (Abstr.)

29. Green, D., and E. V. Potter. 1976. Platelet-bound ristocetin aggregation factor in normal subjects and patients with von Willebrand's disease. J. Lab. Clin. Med. 87: 976-986.

30. Forbes, C. D., and C. R. M. Prentice. 1973. Aggregation of human platelets by purified porcine and bovine anti-hemophilic factor. Nat. New Biol. 241: 149-150.

31. Donati, M. B., G. de Gaetano, and J. Vermylen. 1973. Evidence that bovine factor VIII, not bovine fibrinogen, aggregates human platelets. Thromb. Res. 2: 97-103.

32. Bithell, T. C., S. J. Parekh, and R. R. Strong. 1972. Platelet-function studies in the Bernard-Soulier syndrome. Ann. N. Y. Acad. Sci. 201: 145-160.

33. Floyd, M., W. Burns, and D. Green. 1977. On the interaction between ristocetin and the ristocetin cofactor. (RCOF). Thromb. Res. 10: 841-850.

34. Weiss, H. 1975. Platelet physiology and abnormalities of platelet function. N. Engl.J. Med. 293: 531-540, 580-587.

35. Jaffe, E. A., L. W. Hoyer, and R. L. Nachman. 1974. Synthesis of von Willebrand factor by cultured human endothelial cells. Proc. Natl. Acad. Sci. U. S. A. 71: 1906-1908.

36. Fass, D. N., F. Booyse, J. C. Lewis, and E. J. W. Bowie. 1977. The interaction of the platelet and von Willebrand factor. Thromb. Haemostasis 38: 335. (Abstr.)

37. McPherson, J., and M. B. Zucker. 1976. Platelet retention in glass bead columns: adhesion to glass and subsequent platelet-platelet interactions. Blood. 47: 55-67. 